\title{
O Grande Gasoduto do Sul: impactos sobre a integração regional e o desenvolvimento sul-americano
}

The Great Southern Gas Pipeline: impacts on South American regional integration and development

Bruna Coelho Jaeger ${ }^{1}$

\section{RESUMO}

O objetivo do artigo é analisar o projeto Grande Gasoduto do Sul como importante obra de infraestrutura para a integração sul-americana. Conclui-se que o gasoduto apresenta grandes impactos para a integração regional e para a geopolítica da América do Sul, especialmente para Argentina, Brasil e Venezuela. Assim, a decisão de não o construir afeta o Centro de Decisão Energética regional em face das ameaças externas.

Palavras-chave: Gasoduto do Sul; integração regional; infraestrutura.

\begin{abstract}
The aim of the paper is to analyze the project "Great Southern Gas Pipeline" as an important infrastructure project for South American integration. It is concluded that the gas pipeline has major impacts on regional integration and the geopolitics of South America, especially to Argentina, Brazil and Venezuela. Thus, the decision of not to build it affects Regional Energy Decision Center facing external threats.
\end{abstract}

Keywords: Southern Gas Pipeline; Regional Integration; Infrastructure.

\section{Introdução}

O presente artigo almeja analisar o projeto do Grande Gasoduto do Sul (também chamado de Gasoduto Venezuela-Argentina ou simplesmente Gasoduto do Sul) como grande obra de integração física sul-americana. A integração infraestrutural é um dos aspectos estruturantes do processo de integração regional. Na América do Sul, esse

\footnotetext{
1 Mestra em Estudos Estratégicos Internacionais pela Universidade Federal do Rio Grande do Sul (PPGEEI-UFRGS), Porto Alegre, Brasil. Contato: brunacjaeger@gmail.com.
} 
processo ainda não está consolidado, pois enfrenta dificuldades em atingir seus objetivos. Os investimentos e a oferta adequada de infraestrutura trazem impactos positivos e de interesse social à produção, assim como maior competitividade e geração de empregos e de renda, que se multiplicam por toda a economia (PADULA, 2011). Desse modo, este texto relaciona-se com as funções básicas do Estado, aquelas ligadas à capacidade estatal, definida aqui como a capacidade do Estado de oferecer segurança, direitos, bem-estar e serviços, assim como de extrair recursos da sociedade (TILLY, 2013).

Para atingir seu objetivo, inicialmente o artigo apresenta a importância da infraestrutura para a integração regional. A seguir, empreende-se uma breve análise acerca da atual conjuntura geopolítica do gás natural na América do Sul. Na terceira seção, apresentam-se o Gasoduto do Sul, suas especificidades e seu potencial para o fortalecimento da integração sul-americana. Nesse sentido, busca-se avaliar os seus impactos sobre os principais atores estatais referentes ao projeto, ou seja, Argentina, Venezuela e Brasil. Por fim, na última seção, procura-se avaliar as causas do fracasso do projeto, perguntando-se por que a sua construção não foi efetivada. Ao final, conclui-se que há um enorme potencial desperdiçado em relação à integração energética regional e que o Gasoduto do Sul fortaleceria a América do Sul de forma autônoma e estratégica.

\section{Infraestrutura como elemento da integração regional}

A infraestrutura deve ser entendida como um dos pilares básicos de um processo de integração regional, tal como economia, cultura, instituições políticas e defesa. A integração física de uma região é fundamental, segundo Maria Regina Soares de Lima (2007), pois é o fator que amarra os países ao processo, sobrevivendo às mudanças governamentais. $\mathrm{Na}$ atual conjuntura global, a integração regional é uma possibilidade de os países em desenvolvimento fazerem parte de polos de poder com influência global. A infraestrutura é essencial para que esse cenário se efetive, pois incrementa os ganhos de comércio, a competitividade e a produtividade através da formação de cadeias produtivas regionais. Principalmente, é fundamental para o desenvolvimento socioeconômico, a redução das assimetrias regionais, a segurança e a defesa regional por meio de um planejamento estratégico conjunto. 
No caso da integração sul-americana, a infraestrutura é crucial para que o processo avance e se consolide. Os espaços e as redes logísticas de integração carregam a herança de uma economia historicamente agroexportadora, devido à falta de recursos e de planejamento, assim como devido aos desafios naturais e geográficos. Dessa forma, a infraestrutura foi capilarizada em torno dos portos de exportação com baixíssimo nível de integração entre as economias nacionais (PAZ, 2011). A condição bioceânica da América do Sul favoreceu a ocupação demográfica nas regiões litorâneas. Contudo, não gerou vantagens geopolíticas. Na costa atlântica, foram as bacias hidrográficas que permitiram a vinculação do litoral com o interior. Já na costa do Pacífico, o domínio colonial formou uma unidade andina, desvinculada do interior, cuja integração ao Atlântico sempre teve que transpor a barreira dos Andes. Segundo Costa (2011), a análise da ocupação da América do Sul indica a existência de um dualismo geopolítico sul-americano, mas não de uma dualidade de opostos, tal como indicam os autores Buzan e Wæver (2003). Pelo contrário, desde os anos 2000 há uma tendência de atração natural de cooperação entre as regiões.

No século XIX, foi predominante o transporte ferroviário na América do Sul, o qual se consolidava como o principal meio para o comércio e a integração. A partir dos anos 1950, devido a pressões políticas da indústria automobilística, bem como à maior concorrência advinda da modernização, as redes de integração logística nos mercados nacionais foram estruturadas em função do padrão rodoviário. A ênfase nesse modal trouxe maiores custos de transporte e impactos negativos em termos ambientais (PAZ, 2011). Ao longo do século XX, destacaram-se na região os esforços no investimento infraestrutural devido à onda desenvolvimentista na América do Sul, que tinha como objetivo superar os grandes gargalos estruturais nos setores de energia, transportes e comunicações. Contudo, essa tendência foi revertida na década de 1990 devido às reformas neoliberais. No campo da infraestrutura, houve um aumento dos investimentos privados através das privatizações, em detrimento da atuação estatal. No entanto, esse aumento não foi suficiente para compensar a queda dos investimentos públicos no setor, tanto em quantidade quanto em qualidade.

A criação da Iniciativa para a Integração da Infraestrutura Regional SulAmericana (IIRSA) foi concebida dentro da proeminência ideológica dos governos 
neoliberais na região. A IIRSA foi criada em 2000, sob iniciativa brasileira, na I Reunião dos Chefes de Estado da América do Sul. Em seus primeiros anos de existência, a IIRSA foi articulada para atrair mais investimento externo, estando sob influência direta de instituições financeiras multilaterais. Dessa forma, os projetos de infraestrutura para a integração foram estabelecidos em função da lógica de regionalismo aberto, ou seja, de aumento dos fluxos comerciais voltados para fora da região. 0 Comitê de Coordenação Técnica da IIRSA era formado pelo Banco Interamericano de Desenvolvimento (BID), pela Corporação Andina de Fomento (CAF) e pelo Fundo Financeiro para o Desenvolvimento da Bacia do Prata (Fonplata). Essas instituições são tradicionalmente influenciadas por outros órgãos internacionais, tais como o Banco Mundial, assim como pelo interesse de investidores externos. Segundo Padula (2011), os dois fundamentos orientadores da IIRSA são o regionalismo aberto e a coordenação público-privada. Os demais princípios são a sustentabilidade econômica, social, ambiental e políticoinstitucional, o aumento do valor agregado do produto, tecnologias da informação, convergência normativa e a formação de eixos de integração e desenvolvimento (EID) (PADULA, 2011).

\section{Mapa 1 - Eixos de integração e desenvolvimento da IIRSA}

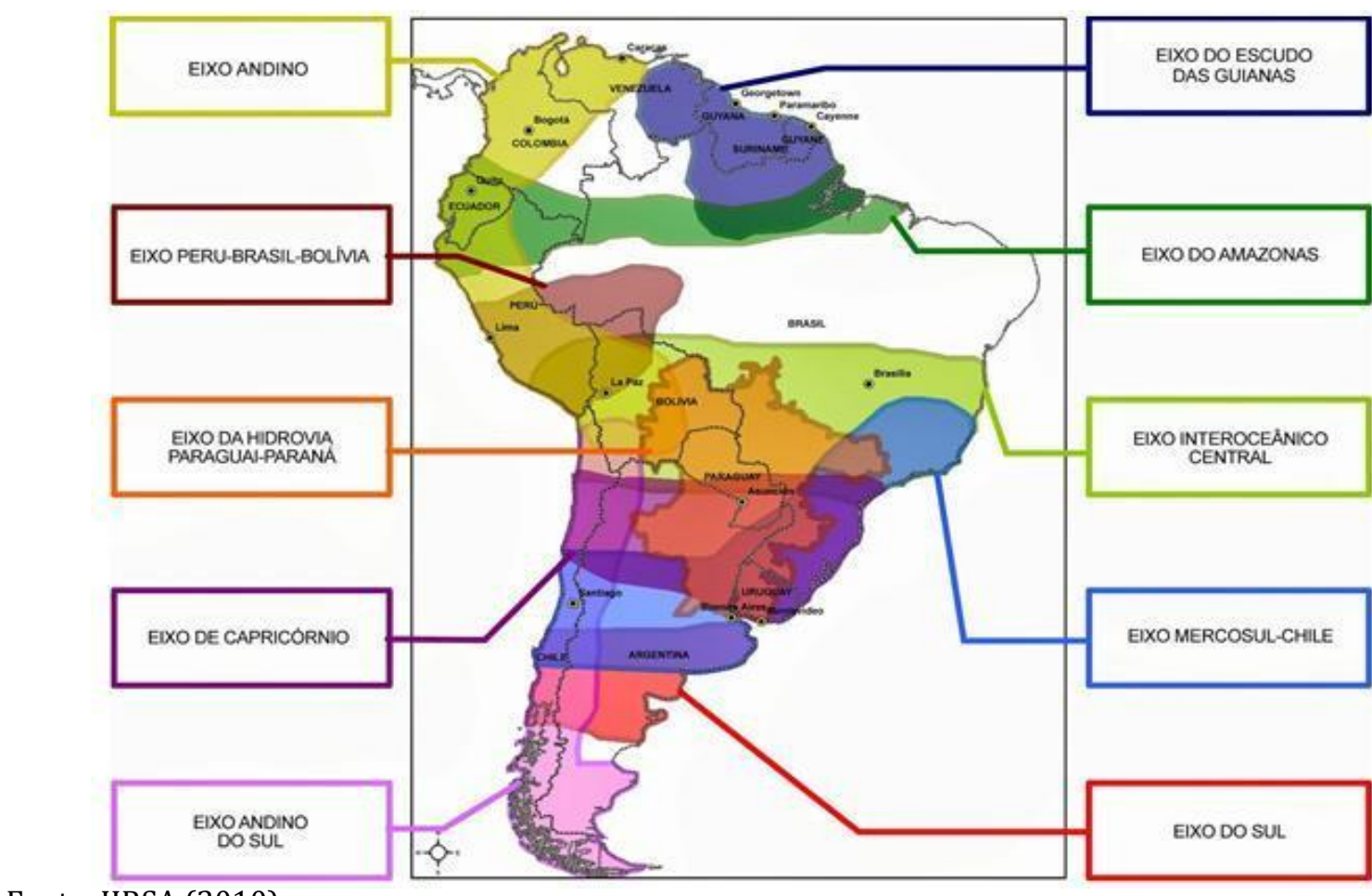

Fonte: IIRSA (2010) 
Basicamente, os EID são faixas de territórios multinacionais nas quais se concentram espaços naturais, assentamentos humanos, zonas produtivas e fluxos comerciais (IIRSA, 2010), como pode ser visualizado no mapa 1 . O conceito de EID permitiu identificar e gerar consenso quanto aos projetos de integração infraestrutural no marco de um processo de planificação territorial indicativa. Revela-se como uma visão integral da infraestrutura, na qual se busca articular, de maneira direta, projetos e territórios. Com isso, procura-se impulsionar a eficiência dos investimentos e o desenvolvimento de cadeias logísticas integradas, além de melhorar a qualidade de vida da população. Segundo a Carteira de Projetos da IIRSA de 2010, os EID não têm como objetivo criar corredores que apenas facilitem o comércio. Mais do que isso, pretendem ser vetores de desenvolvimento socioeconômico integral, envolvendo não somente transportes, mas também energia, comunicações, redes produtivas, meio ambiente, capital humano e capacidades institucionais, defensivas e tecnológicas (IIRSA, 2010).

Entretanto, muitas críticas são atribuídas à constituição dos EID. Primeiramente, por mais que tenham um grande potencial para a integração estratégica, visando também à redução das assimetrias regionais, eles, em geral, privilegiam mais a lógica dos corredores de exportação e de projetos que sejam mais capazes de atrair investimento em vez de objetivos estratégicos e sistêmicos. Além disso, em certa medida, reforçam disparidades e o perfil de regionalismo aberto, pois a maioria dos eixos é estruturada no sentido leste-oeste e não norte-sul, e há um enorme vazio na região amazônica e do Nordeste brasileiro. Sobretudo, não consideram os elementos socioeconômicos que separam os espaços, mas apenas as barreiras físicas (COUTO, 2013). De acordo com Raphael Padula:

\footnotetext{
Seguindo uma visão puramente geoeconômica da região, os EIDs organizariam o espaço regional em torno de franjas multinacionais que concentram fluxos de comércio atuais ou potenciais, nos quais se busca estabelecer um padrão mínimo comum de qualidade de oferta de infraestrutura, a fim de apoiar as atividades produtivas específicas de cada EID, para o mercado interno (possivelmente formando cadeias produtivas) e para exportação (apoiando a competitividade global). Sobretudo, pode-se constatar que toda racionalidade geográfica de eixos e a concepção geopolítica para a integração foram submetidas à racionalidade econômica neoliberal dominante (PADULA, 2011, p. 167).
} 
Sendo assim, a IIRSA avançou de forma flexível, sem buscar uma forma centralizada e indutora para estabelecer os investimentos. Segundo Gonçalves et al. (2003), no Brasil, houve dois nomes de influência para a constituição dos EID. 0 principal, Eliezer Batista², propunha especialmente a conexão dos centros produtores de commodities aos mercados globais através de corredores de exportação. Já Paulo Dante Coelho $^{3}$ defendia o conceito de "macroeixos de desenvolvimento" para a retomada do planejamento territorial no país. A primeira visão acabou sendo a dominante, com ampla visibilidade.

No início do primeiro governo Lula, a IIRSA era encarada com desconfiança. De acordo com Leandro Couto (2013, p. 157), “a aceitação da sua inclusão na agenda das relações regionais por parte da diplomacia brasileira impôs-se pelas demandas dos vizinhos". Assim, ainda que o governo tratasse como fundamental a integração física, inicialmente não concordava com os moldes pelos quais ela vinha sendo planejada no subcontinente. Isso se dava especialmente devido à ausência do Banco Nacional de Desenvolvimento Econômico e Social (BNDES) na IIRSA, bem como à grande influência do BID e das reformas neoliberais.

Em 2004, na III Reunião de Chefes de Estado da América do Sul, em Cuzco, a qual formou a Comunidade Sul-Americana de Nações (Casa, futura Unasul), os governos passaram a dar maior atenção à IIRSA e à construção de um modelo diferente de integração. Ainda que a IIRSA tenha mantido seu enfoque no regionalismo aberto, foi consolidada a Agenda de Implementação Consensuada (AIC) 2005-2010, a qual abandonou a visão de área de livre-comércio na América do Sul (PADULA, 2011).

O avanço da IIRSA tem correlação direta com a busca pela ampliação do escopo de integração, antes mais centrado no Mercosul, para todo o subcontinente. Objetivamente, foi posto em prática com o estabelecimento da União das Nações SulAmericanas (Unasul), derivada da Casa. Nesse sentido, o fortalecimento da IIRSA é desdobramento da busca pela convergência dos diversos processos de integração sul-

\footnotetext{
2 Ministro da Secretaria de Assuntos Estratégicos da Presidência da República no governo Itamar Franco e ex-presidente da Companhia Vale do Rio Doce.

${ }^{3}$ Ex-coordenador de planejamento regional do Ipea.
} 
americana e da procura por ampliar o escopo político das decisões relativas à construção de infraestrutura regional.

Essas transformações na política sul-americana derivam da onda de ascensão de governos progressistas no subcontinente, iniciada no final dos anos 1990. A chegada de Hugo Chávez Frías ao poder em 1999 representa o início de um processo de ruptura com o perfil de busca por alinhamento ao Consenso de Washington, que prevalecera durante a década de 1990. Essa chamada "primavera sul-americana" tornou-se consolidada com as eleições de Luiz Inácio Lula da Silva no Brasil (2003-2010), Néstor Kirchner na Argentina (2003-2007), Tabaré Vázquez no Uruguai (2005-2010), Evo Morales na Bolívia (2006 - ), Rafael Correa no Equador (2007 - ) e Fernando Lugo no Paraguai (2008-2012) (FUCCILLE, 2014). A convergência programática desses governos abriu espaço para uma agenda mais ampla de cooperação que não aquela voltada apenas às questões comerciais. Essa nova perspectiva mais progressista gerou um fortalecimento da integração regional.

Principalmente a partir de 2008, com a crise econômica e a criação da Unasul, um novo enfoque foi dado à integração regional, com maior participação dos governos e com o advento de uma visão estratégica e sistêmica sobre o processo. Em relação à integração física, o fato mais relevante se deu na criação do Conselho Sul-Americano de Infraestrutura e Planejamento (Cosiplan) em 2010, o qual absorveu a IIRSA e implementou um caráter mais político e estratégico à integração infraestrutural, que prevalecia sobre as instituições financeiras multilaterais e sobre os interesses externos. Certamente, não se deve menosprezar a importância da IIRSA, na medida em que a consolidação e implementação de uma agenda regional de infraestrutura, em consenso entre as 12 nações da América do Sul, nunca foi alcançada anteriormente e avançou mesmo sob mudanças de governos. Dessa forma, representou um impulso importante no processo de integração física, configurando-se como a base institucional para o seu fortalecimento. Entretanto, a IIRSA assume caráter estruturante a partir da criação da Unasul, em 2008, e da sua conversão em Cosiplan, em 2010.

Por conseguinte, importa considerar a integração infraestrutural como chave para o aproveitamento da riqueza de recursos naturais na América do Sul. "Com os recursos de que dispõe, a América do Sul é uma das regiões mais ricas do mundo. Não 
carece nem de alimentos, nem de meios para produzir energia e nem de outros recursos para promover um processo de desenvolvimento industrial" (COSTA, 2011, p. 9). Especialmente no que tange ao potencial hidrográfico do subcontinente, é possível vertebrar uma integração energética e de transportes através dos caudalosos rios sulamericanos. Nenhuma outra região do mundo apresenta as condições físicas e ambientais para integrar três grandes bacias hidrográficas como a América do Sul. Além disso, a região destaca-se na produção de minerais, a qual deveria transcender ao mercado externo e investir no seu aproveitamento para a produção de bens de alto valor agregado dentro da América do Sul.

Da mesma forma é o caso da produção de petróleo e gás. As condições energéticas necessárias para a integração gasística da América do Sul estão todas presentes: reservas de gás suficientes e distribuídas de maneira a induzir a integração, com fortes expectativas e potencial de crescimento da demanda e da produção (PAZ; NUNES, 2011). O projeto do gasoduto Venezuela-Brasil-Argentina (Gasoduto do Sul), que ligaria as reservas venezuelanas aos centros consumidores do sul do continente, criaria demanda para o gás venezuelano e, a médio prazo, resolveria o problema energético argentino, que possui sua matriz concentrada no gás e reservas somente para mais dez anos (PAZ; NUNES, 2011).

Portanto, no que diz respeito à integração de infraestrutura na América do Sul, devem ser incentivadas as ações que promovam o aproveitamento das complementaridades entre os vizinhos. Somente uma visão estratégica de planejamento conjunto para a infraestrutura pode impulsionar no subcontinente a formação de cadeias produtivas regionais e a geração de energia integrada. Darc Costa (2011) sugere que seja garantido um mínimo de $6 \%$ do PIB da região para investimentos em infraestrutura para os próximos 30 anos. Hidrovias, ferrovias, estradas, portos, gasodutos, oleodutos, hidrelétricas, refinarias, redes de comunicação e postos de fronteira configuram-se como a base da integração regional. Especialmente em relação à redução das assimetrias presentes na América do Sul, a integração infraestrutural é chave para o desenvolvimento de áreas interiores e afastadas dos grandes centros, tal como a Amazônia, o Centro-Oeste brasileiro, a Bolívia e o Paraguai. A diminuição das desigualdades econômicas e sociais é fundamental para garantir estabilidade interna em 
um país ou região. Além do mais, somente a integração física na América do Sul permite que haja o aproveitamento da sua posição estratégica. Similar à América do Norte, o subcontinente sul-americano encontra-se distante do Heartland ${ }^{4}$ e do crescente interior (ou Rimland ${ }^{5}$ ) eurasiano. Portanto, é um espaço destinado à integração pela sua própria exclusão (COSTA, 2011). A América do Sul possui vantagens estratégicas e geopolíticas subaproveitadas, tais como a condição bioceânica e o seu interior relativamente bem protegido $^{6}$, as quais podem ser impulsionadas através da integração infraestrutural, garantindo uma posição de destaque da região no sistema internacional.

\section{A geopolítica do gás natural na América do Sul}

0 gás natural é o combustível do futuro. 0 consumo mundial triplicou nas últimas três décadas e a demanda pode aumentar mais 50\% nos próximos 20 anos. Atualmente, o consumo de gás natural representa em torno de $70 \%$ do consumo de petróleo (YERGIN, 2014). Uma das principais razões reside no fato de ser esse um recurso com emissão relativamente baixa de carbono. Contudo, pode-se dizer que o grande incremento à produção de gás natural é devido à descoberta de grandes reservas, bem como ao desenvolvimento tecnológico e ao investimento em

\footnotetext{
${ }^{4} \mathrm{O}$ conceito geopolítico de Heartland foi desenvolvido por John Halford Mackinder no início do século XX. Para o autor o Heartland (ou área-pivô) seria o coração da ilha-mundo (World-Island), região que abrange a Ásia continental, a Europa e a África. Essa região (Heartland) seria rica em potencial agrícola, mineral, securitário - pois é de difícil acesso e nunca foi plenamente dominada por nenhum império ao longo da história. Nesse sentido, poderia ser considerada uma região inexpugnável. Por isso, a ideia de que "quem domina o Heartland, domina o mundo". Em termos geográficos, a delimitação da área-pivô variou ao longo do tempo, mas, grosso modo, corresponde à região da Ásia Central, tendo como limites, ao sul, o Himalaia, e ao norte, o Ártico.

50 conceito de Rimland foi estabelecido por Nicholas Spykman. Em contraposição à perspectiva de Mackinder, Spykman defende que é o controle das fímbrias (região que abrange as penínsulas e as áreas marginais da Eurásia) que permite a projeção de poder para o continente e para os mares. Nesse sentido, seus estudos têm como base a análise do período de hegemonia britânica, no qual o controle das regiões peninsulares permitiu ao Reino Unido estabelecer domínio no subcontinente indiano e em grande parte da Ásia.

${ }^{6}$ Ressalta-se a teoria do poder marítimo de Mahan, cuja obra de geopolítica clássica salienta o papel central da estratégia de controle dos rios. Em sua obra, Mahan (1894) discorre sobre a vantagem competitiva dos Estados Unidos como decorrência do controle sobre a vasta hidrovia natural do complexo Mississippi-Missouri-Ohio, coincidente com sua principal região produtora de alimentos e matériasprimas. Além disso, a condição bioceânica é um dos conceitos geopolíticos utilizados por Mahan, o qual igualmente ilustra as vantagens estratégicas dos Estados Unidos. Por outra via, a América do Sul apresenta enorme potencial para aproveitar essas mesmas vantagens, que estão ligadas ao desenvolvimento regional e à capacidade para transferir forças navais de um oceano para o outro rapidamente. Ademais, a América do Sul pode apropriar-se de outro conceito impulsionada através da integração infraestrutural, garantindo uma posição de destaque da região no sistema internacional.
} 
infraestrutura. Por ser um combustível flexível, ou seja, com variadas possibilidades de utilização, há incentivo para a tecnologia aumentar a disponibilidade do gás natural. Nesse sentido, há avanços na perfuração convencional e não convencional, na expansão do $\mathrm{GNL}^{7}$ em escala muito maior e, especialmente, na capacidade de transporte do combustível via gasodutos de longa distância.

Segundo Marina Boas (2004), as características técnicas da produção de gás natural demandam um alto nível de coordenação entre todos os elos da cadeia produtiva, assim como as demais indústrias de rede. Dessa forma, produção, transporte, comercialização e distribuição precisam estar sincronizados entre o produtor e o consumidor. Durante a década de 1990, as reformas neoliberais das economias sulamericanas influenciaram diretamente a construção de infraestrutura, em particular no setor gasístico. As iniciativas se deram especialmente no âmbito de empresas internacionais, de acordo com a racionalidade privada de interesses. Nesse sentido, desde então, se tem assistido a uma estratégia descoordenada de integração energética na América do Sul, com pouca participação estatal e sem os benefícios que poderiam advir da sinergia de uma integração com viés estratégico. Por exemplo, as válvulas de abastecimento dos veículos a gás. Enquanto, na Bolívia e na Argentina, as válvulas têm 12,7 mm de diâmetro, no Brasil são 11,1 mm. Ou seja, os veículos a gás que saem do Brasil não podem ser abastecidos nesses vizinhos e vice-versa (PAZ; NUNES, 2011).

Para a América do Sul, o gás natural representa um potencial subaproveitado para o fortalecimento da integração regional. Tal como pontuam Paz e Nunes (2011), as condições energéticas estão todas presentes: reservas de gás suficientes e distribuídas de forma a induzir a integração, com grandes expectativas de aumento da demanda e da produção. Inclusive, apesar de ainda importarmos grandes volumes do Oriente Médio e de outras regiões, a soma das reservas presentes nos países sul-americanos habilita a autossuficiência regional quanto ao recurso. As reservas venezuelanas provadas poderiam sustentar o subcontinente por mais de 50 anos, sem contarmos o grande potencial das reservas prováveis.

\footnotetext{
7 GNL é a sigla de gás natural liquefeito, cujo desenvolvimento representou uma revolução no consumo energético mundial na medida em que permite o transporte do combustível por via marítima.
} 
Segundo o British Petroleum Statistical Review de 2015, a Venezuela tem disparadamente as maiores reservas provadas de gás natural da América do Sul, com 197,1 trilhões de $\mathrm{m}^{3}$. A Bolívia possui 10,5; a Argentina, 11,6; e o Brasil, 16,4 trilhões de $\mathrm{m}^{3}$. Em 2014, a Venezuela produziu 28,6 bilhões de $\mathrm{m}^{3}$; a Bolívia, 21,4; o Brasil, 20,0; e a Argentina, 35,4 bilhões de $\mathrm{m}^{3}$. Desde 2007, a produção argentina vem decaindo ano a ano. A Argentina apresenta o maior consumo da região: foram 47,2 bilhões de $\mathrm{m}^{3}$ em 2014, enquanto o Brasil consumiu 39,6 no mesmo ano, ou seja, a Argentina precisou importar 11,8 bilhões de $\mathrm{m}^{3}$ em 2014. Desses, 5,4 foram da Bolívia, através de gasodutos. 0 restante foi importado especialmente de Trinidad e Tobago, Catar, Nigéria, Noruega e outros países europeus. Já o Brasil precisou importar 19,6 bilhões de $\mathrm{m}^{3}$ em 2014, sendo 11,1 da Bolívia, através do $\mathrm{Gasbol}^{8}$, e o resto foi importado principalmente de Trinidad e Tobago, países do norte da África, do Oriente Médio e de alguns países europeus.

Assim, a partir dos dados apresentados, infere-se o seguinte: (i) a Venezuela apresenta grandes reservas de gás natural para abastecimento do subcontinente sulamericano; (ii) a Argentina é um grande consumidor do recurso e apresenta dependência do combustível devido à sua matriz energética; contudo, apesar das grandes reservas presentes nos vizinhos, o país importa de países de fora da região mais da metade do volume consumido; (iii) o Brasil apresenta números similares aos argentinos; entretanto, a dependência do gás natural é muito menor devido à sua maior diversidade de matriz energética; (iv) apesar de ter reservas inferiores e menor produção de gás natural em relação à Venezuela, a Bolívia é o maior exportador do recurso para os vizinhos; (v) dessa forma, conclui-se que, para a integração gasística na América do Sul, um dos determinantes centrais é a presença de gasodutos que viabilizem o comércio intrarregional. No entanto, o subcontinente carece de gasodutos que deem conta de sua produção. Inclusive, por mais anti-intuitivo que pareça, a Venezuela praticamente não possui conexões gasíferas com os vizinhos, com exceção de

\footnotetext{
${ }^{8}$ O Gasoduto Brasil-Bolívia, ou Gasbol, possui $3.150 \mathrm{~km}$ de extensão e teve sua construção plenamente concluída no ano de 2010, apesar de ter iniciado sua operação em 1999. 0 gasoduto tem seu início na cidade boliviana de Santa Cruz de la Sierra e seu fim na cidade gaúcha de Canoas, atravessando também os estados de Mato Grosso do Sul, São Paulo, Paraná, Santa Catarina e Rio Grande do Sul, passando por cerca de 4 mil propriedades em 135 municípios.
} 
um pequeno gasoduto que liga a região de Maracaibo à Colômbia. No mapa 2, abaixo, podem ser vistos todos os gasodutos existentes na América do Sul.

\section{Mapa 2 - Gasodutos sul-americanos}

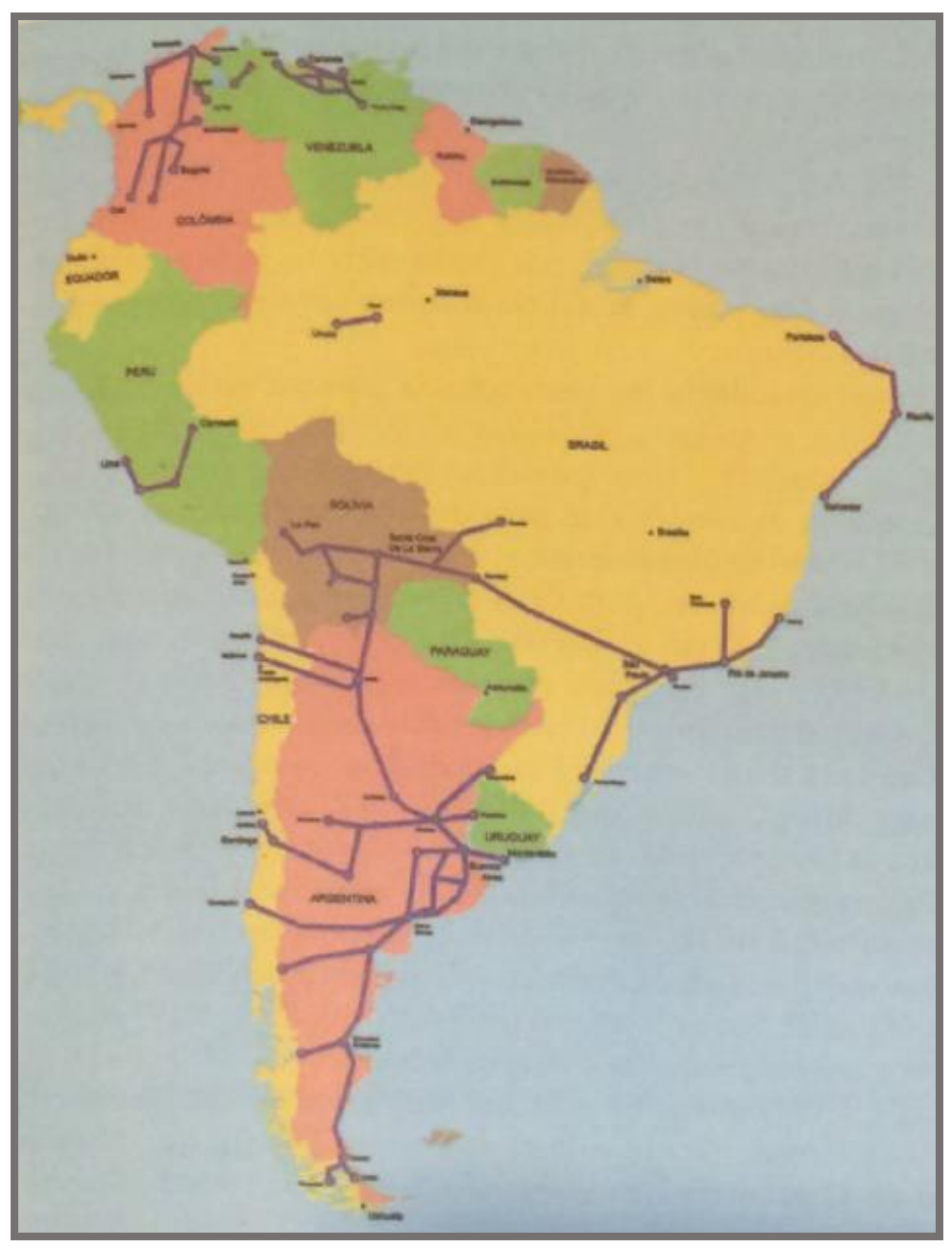

Fonte: PAZ; NUNES, 2011.

Portanto, para que a América do Sul avance no processo de integração regional, os investimentos em infraestrutura são fundamentais. Nesse âmbito, os gasodutos, apesar de demandarem um alto investimento inicial, têm um gasto operacional e de manutenção relativamente muito baixo. É nesse contexto que surge o projeto do Gasoduto do Sul, ligando o gás venezuelano à Argentina através do Brasil, com possíveis ramificações à Bolívia e ao Uruguai.

\section{0 projeto do Grande Gasoduto do Sul}


Lançado em 9 de dezembro de 2005, na XXIX Cúpula do Mercosul, em Montevidéu, o Grande Gasoduto do Sul (também chamado de Gasoduto Venezuela-Argentina ou simplesmente Gasoduto do Sul) nasceu do entendimento mútuo entre os ministros da Energia de Brasil, Argentina e Venezuela sobre a importância da integração energética sul-americana. Originalmente, o projeto foi formulado para ser construído pela Petrosul, instância política de coordenação de ações nas áreas energética e petroleira, cuja criação foi acordada na mesma ocasião, mas que, contudo, jamais foi adiante. O projeto seria financiado pela empresa petroleira venezuelana PDVSA, pela CAF e pela Caixa Econômica Federal, com abertura também para outros investimentos públicos e privados. Em abril de 2007, ocorreu, na ilha de Margarita, na Venezuela, a I Cúpula Energética Sul-Americana. No encontro entre líderes da região, foi reafirmada a construção do Gasoduto do Sul como principal obra do Anel Energético Sul-Americano, cujo projeto criaria uma ampla rede de gasodutos por todo o subcontinente a partir de ramificações do Gasoduto do Sul e do Gasbol.

Somando-se às ramificações previstas, o gasoduto teria em torno de 9 mil km de extensão, de Puerto Ordaz até Buenos Aires, como pode ser visto no mapa 3, abaixo. Segundo o mapa, o Gasoduto do Sul é representado pelo tracejado em vermelho, enquanto os gasodutos já existentes são as linhas contínuas na cor azul. As linhas pontilhadas em azul representam outros projetos. Além disso, ao mapa adicionam-se quadros comparativos entre os países da região em relação às reservas e à demanda por gás natural. 


\section{Mapa 3 - 0 Gasoduto do Sul em perspectiva comparada}

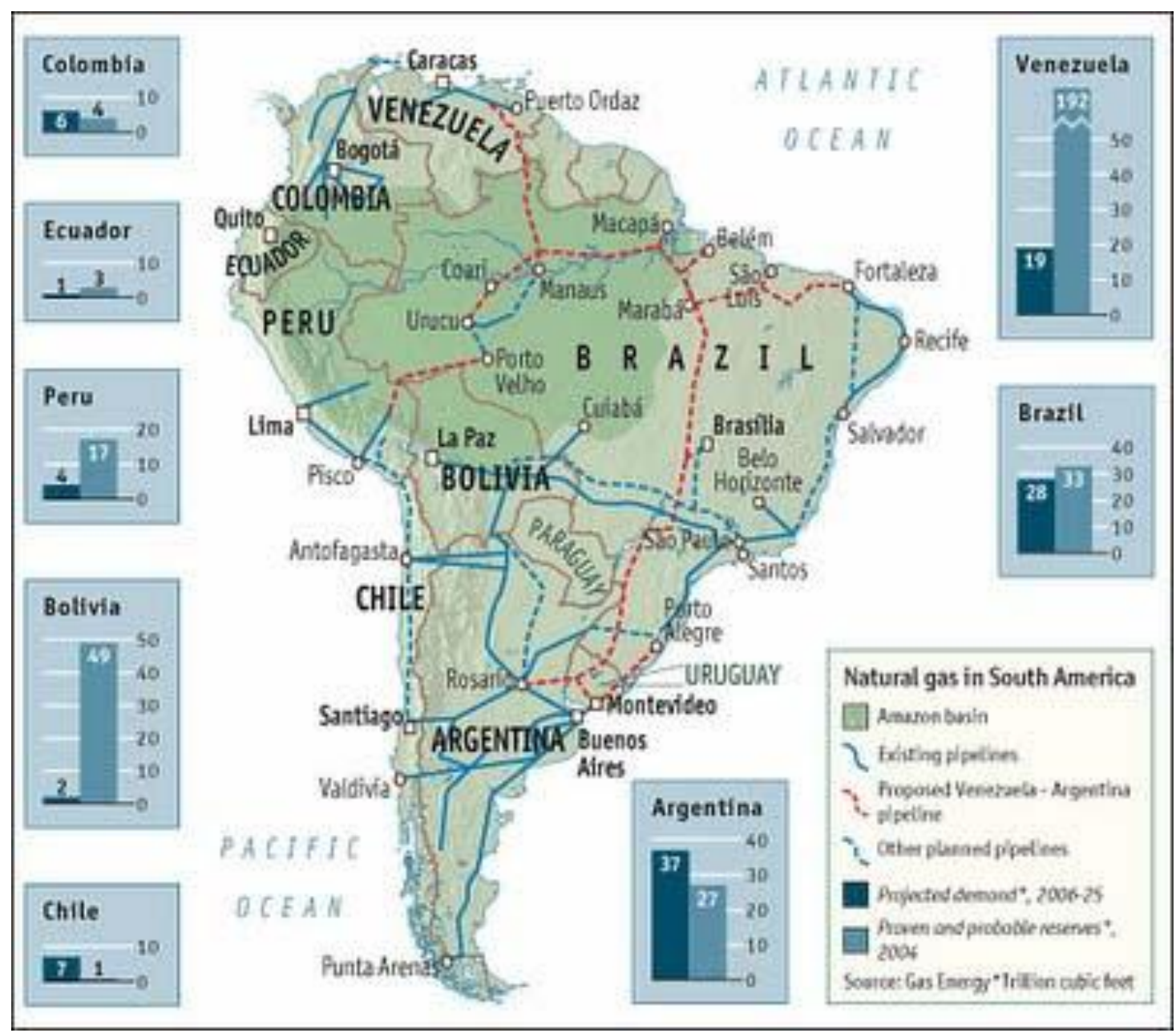

Fonte: International Political Economy Zone (Ipezone), 2007

Dessa forma, destaca-se o grande vazio no interior do continente em contraste com a rede de gasodutos entre Argentina, Bolívia e Chile. Assim como a Argentina, o Chile também possui déficit no recurso, o qual surpreendentemente é importado da Argentina9 ${ }^{9}$. Ou seja, em que pese o fato de a Argentina ter um déficit em termos de abastecimento, por ser um grande produtor, exporta gás para o Chile. Assim, não há uma racionalização dos recursos regionais, o que acaba ampliando os custos energéticos.

Mais uma vez destaca-se a preponderância do fator infraestrutura existente como determinante para a integração. "O certo é que qualquer proposta de integração sul-americana depende fundamentalmente de três atores. São eles a Venezuela pela

\footnotetext{
${ }^{9}$ Devido à histórica disputa territorial e diplomática entre Chile e Bolívia, não há ligações gasíferas entre os dois vizinhos.
} 
ousadia, a Argentina pela coragem e o Brasil pelo tamanho" (MARINGONI, 2009, p. 182). Nesse sentido, o Gasoduto do Sul ligaria as reservas de gás venezuelanas aos centros consumidores do sul do continente, criaria demanda para o gás venezuelano e a médio prazo resolveria o problema energético argentino - e, por consequência, também o chileno (PAZ; NUNES, 2011).

À Venezuela o gasoduto traria grandes benefícios, não somente econômicos, mas também sociais. Atualmente, o país enfrenta séria crise política e instabilidade social. Desde a morte do presidente Hugo Chávez, o já fragilizado pacto social instaurado pela revolução venezuelana vem se esfacelando. 0 país vive grave crise econômica, com alta inflação e problemas cambiais. Dessa forma, o governo não consegue mais manter sua base política através de programas sociais como antes. Soma-se a isso o aumento de força por parte da oposição e da classe conservadora neoliberal. Assim, o atual cenário é de uma quase guerra civil, com incremento da violência e enfrentamentos entre a parcela da sociedade que apoia o governo e aqueles que se opõem. Ao governo Nicolás Maduro falta a habilidade política do ex-presidente, tanto no âmbito interno quanto no regional. Pode-se dizer que as atuais bases da integração sul-americana de cunho estratégico e progressista foram lançadas pelo presidente Hugo Chávez, aliando-se aos presidentes Lula da Silva e Néstor Kirchner para o fortalecimento regional. Nesse sentido, o Gasoduto do Sul, além de impulsionar a integração regional e retomar as bases do processo, traria benefícios ao desenvolvimento econômico venezuelano que não podem ser ignorados. Visto que grande parte da atual crise político-social advém da recessão econômica no país, a geração de emprego e renda através do gasoduto teria enorme potencial para amenizar a conjuntura atual de tensões sociais.

Em relação à Argentina, as consequências da construção do Gasoduto do Sul seriam extremamente positivas. 0 país formou sua base energética com forte dependência do gás natural. Como visto nos mapas acima, o país já apresenta uma densa malha de gasodutos em relação aos vizinhos. Contudo, sabe-se que não é o suficiente para abastecer a demanda nacional. Por mais que a Bolívia cumpra seu papel de grande fornecedor de gás na América do Sul, suas reservas e a capacidade dos gasodutos existentes não sustentarão o consumo dos vizinhos nas próximas décadas. Assim, a importação de GNL extrarregional teria um enorme incremento, o que representa um 
grande potencial dispersado em relação às reservas regionais. 0 gás natural transportado por gasodutos tem um custo muito menor em relação ao GNL. Além disso, construir infraestrutura regional fortalece o centro de decisão energética na América do Sul (OLIVEIRA, 2012), habilitando a região a fortalecer-se em uma conjuntura de incerteza global quanto à segurança energética e aos conflitos por recursos naturais.

Como visto, a infraestrutura é um elemento central para o progresso econômico, social e securitário de um Estado ou região. Por essa via, a promoção de infraestrutura é fundamental para o conceito, formulado por Celso Furtado (1962), de centro de decisão, que resumidamente concerne à "capacidade de gerir o próprio desenvolvimento econômico" (MARTINS, 2008, p. 14), ou seja, é a capacidade de controlar as tecnologias e a produção central, especialmente as atividades nucleadoras do desenvolvimento econômico (OLIVEIRA, 2012). A nacionalização do centro de decisão, dessa forma, é uma etapa crucial no desenvolvimento de um Estado, na medida em que, do contrário, decisões podem ser tomadas por atores estrangeiros que não comungam dos mesmos interesses e objetivos de desenvolvimento da nação. As mesmas conclusões são válidas para um processo de integração regional, tal como o sul-americano. Visto que infraestrutura é um dos pilares básicos que permitem a produção e a geração de tecnologia em uma economia, o seu controle e promoção podem ser encarados como elementos centrais para o centro de decisão de um Estado ou região. Além disso, a infraestrutura assume também o papel de mecanismo transformador de poder, a qual, segundo Oliveira (2012), pode transformar recursos de poder em capacidades convencionais e estratégicas. Nesse sentido, com vistas ao fortalecimento da autonomia regional, é central que os Estados da América do Sul, no âmbito das instituições regionais, possam planejar e ter controle sobre as infraestruturas críticas. Isso não quer dizer que não possa haver parceria com a iniciativa privada, apenas que caberia aos Estados a responsabilidade de planejamento e decisão acerca de quais projetos seriam prioritários para o desenvolvimento regional.

Já para o Brasil, o Gasoduto do Sul representa uma grande oportunidade para o país avançar na liderança regional. Em termos de inserção internacional, a infraestrutura regional configura-se como elemento-chave para o fortalecimento da América do Sul. Os desafios oriundos do processo de recomposição hegemônica 
demandam uma maior capacidade econômica e defensiva (MARTINS, 2013). Para o Brasil, não há como dissociar suas potencialidades de ascensão no sistema internacional do projeto de integração sul-americana (VIZENTINI, 2003). Esse projeto passa necessariamente pela construção de uma rede integrada de infraestrutura, cujos objetivos vão ao encontro dos princípios norteadores da política externa brasileira e da Estratégia Nacional de Defesa (BRASIL, 2008). Portanto, as respostas a esses desafios podem estar, ao que tudo indica, no estabelecimento de um centro de decisão econômico e energético em âmbito regional, gerando maior autonomia para a região. 0 Brasil, diante desse quadro, é o ator que possui meios para tal e, portanto, deve assumir um papel protagonista nesse processo. Por razões diversas, como falta de acesso aos dados financeiros das empreiteiras e estimativa imprecisa dos custos totais, é difícil estabelecer com precisão com qual parcela o Brasil arcaria. Entretanto, é o ator que possuiria interesse e capacidades para alavancar o processo de integração regional. Cabe destacar que muitas vezes os benefícios do estabelecimento de infraestruturas regionais integradas não são tangíveis.

Com custos estimados em torno de 20 bilhões de dólares, o que deveria ser o maior projeto de integração infraestrutural na América do Sul tinha previsão de iniciar as obras em 2009 e inaugurar os primeiros trechos em 2013. No entanto, o Grande Gasoduto do Sul nem sequer alcançou as operações iniciais. Apesar disso, pelo exposto acima, fica evidente que os benefícios a médio e longo prazos superam os custos financeiros para a realização da obra.

Pelo fato de não ter saído do papel e pela mudança na conjuntura política sulamericana, restam muitos questionamentos mais específicos sobre a obra. Por exemplo, que tipo de parceria público-privada poderia ser estabelecido para dar andamento ao projeto? Após a desestruturação de parcela significativa das empreiteiras brasileiras, como viabilizar o projeto? Recorrer a parcerias extrarregionais para o projeto é uma alternativa viável e convergente com os interesses regionais? Se sim, de que modo conciliar a busca pela autonomia com a necessidade de financiamento externo para o projeto, já que a crise econômica incidiu diretamente sobre as economias da região? São todas perguntas cujas respostas ainda estão em aberto. 


\section{Causas do fracasso do projeto Gasoduto do Sul}

Atualmente, o processo de integração sul-americana vem passando por uma fase de paralisia e retrocesso. Grandes avanços alcançados na primeira década do século XXI agora são considerados no passado da história regional. Pode-se dizer que o projeto do Grande Gasoduto do Sul encontra-se nesse contexto. Assim como outras grandes obras de infraestrutura, de projetos de cooperação institucional, de segurança e defesa, a América do Sul assiste à janela de oportunidade integracionista tornar-se cada vez menor. $\mathrm{Na}$ atual conjuntura regional de enfraquecimento do projeto político progressista e fortalecimento do conservadorismo e do neoliberalismo, a integração regional pensada de forma autônoma, com elementos estratégicos para o fortalecimento conjunto, começa a ser substituída pelo projeto integracionista que vem de fora, ou seja, com grande influência de potências extrarregionais.

A assinatura de acordos comerciais e de livre-comércio com Estados Unidos ${ }^{10}$ e União Europeia ${ }^{11}$, o fortalecimento da Aliança do Pacífico e o aumento contínuo da presença chinesa indicam que houve falhas na condução da integração regional iniciada nos anos 2000. Afinal, desafiam a capacidade autônoma dos países da região à medida que ampliam a dependência econômico-financeira em relação às potências extrarregionais.

Assim como o governo de Nicolás Maduro, talvez ainda seja cedo para uma avaliação coerente da política externa do governo Dilma Rousseff. Contudo, destaca-se que desde 2011 as iniciativas para a integração sul-americana vêm ficando cada vez mais escassas, especialmente devido à falta de liderança brasileira. Certamente, o contexto de crise econômica mundial, a qual afetou duramente as economias emergentes, pode ser considerado o fator central para a atual conjuntura regional. Ao contrário do que foi feito durante o governo Lula da Silva, o Brasil deixou de apostar em medidas anticíclicas para o enfrentamento da crise e vem se adequando ainda mais aos padrões neoliberais impostos pelos grandes centros econômicos. Ademais, a atual instabilidade política no Brasil advinda de escândalos de corrupção em grandes

\footnotetext{
${ }^{10}$ Nesse contexto destacam-se os acordos bilaterais dos EUA com o Chile, em 2003, com o Peru, em 2005, e com Colômbia, em 2006.

${ }^{11}$ Podem ser destacados os acordos comerciais com Peru e Colômbia, em 2010, e o acordo de livrecomércio com o Chile, em 2003.
} 
empresas de energia e construção afetou de forma decisiva os projetos de infraestrutura integrada na América do Sul. Assim, a presença chinesa vem aumentando justamente nessa área, ocupando o lugar deixado pela liderança brasileira, pois o país asiático percebe, na região, o grande potencial não aproveitado para investimentos.

A morte de Hugo Chávez também pode ser considerada uma das causas da não efetivação do Gasoduto do Sul, visto que o presidente representava um grande impulso à integração regional. A liderança política de Chávez era fortemente apoiada na relação com os vizinhos devido ao seu pensamento de fortalecimento regional conjunto em face das ameaças externas. A entrada da Venezuela no Mercosul foi um avanço nesse sentido. Contudo, não representou o suficiente para lograr a construção do gasoduto, bem como de outros grandes projetos.

Outras razões podem ser atribuídas ao fracasso do projeto, tais como a descoberta de petróleo na camada pré-sal, o que desviou os recursos brasileiros para a sua exploração e diminuiu a urgência por diversificação energética. Além disso, pressões de grupos ambientalistas radicais - muitos deles financiados por grandes empresas e corporações internacionais - também ajudaram a travar o desenvolvimento do Gasoduto do Sul. Dessa forma, o fracasso do projeto insere-se em um contexto amplo e complexo de falhas na integração sul-americana, cujo vácuo de liderança brasileira e de apoio venezuelano faz-se sentir profundamente.

\section{Considerações finais}

O presente trabalho buscou analisar o projeto Grande Gasoduto do Sul como uma importante obra de infraestrutura para a integração sul-americana. Sendo assim, apresentou-se a atual conjuntura geopolítica do gás natural na América do Sul e discutiram-se o projeto e as causas da sua não efetivação. Em especial, procurou-se analisar as consequências que o gasoduto traria para a integração regional sulamericana, principalmente para Argentina, Venezuela e Brasil. Nesse sentido, além de fortalecer o processo integracionista, garantiria o suprimento energético da Argentina, que apresenta restrições do recurso. Para o Brasil, além de aumentar a diversificação energética, contribuiria para a liderança do país na região, devido aos custos do 
financiamento. Para a Venezuela, a abundância do gás natural presente no país seria aproveitada e auxiliaria na resolução das instabilidades sociais internas devido ao maior desenvolvimento econômico proporcionado.

O Gasoduto do Sul, que deveria ser a maior obra de integração infraestrutural na América do Sul, possibilitaria: (i) induzir novas atividades econômicas, pois elevaria a capacidade energética regional, gerando novos projetos de desenvolvimento, bem como fortaleceria a capacidade competitiva, a industrialização e a geração de emprego e renda na América do Sul; (ii) aumentar a oferta de energia e reduzir o seu custo, o que permitiria resolver o problema do crescente consumo e da produção insuficiente; (iii) integrar energeticamente a América do Sul, ao viabilizar a autossuficiência e a independência nesse setor estratégico, e fortaleceria a posição política e econômica sulamericana no sistema internacional, impulsionando o desenvolvimento dos países da região e superando grandes gargalos estruturais.

Entretanto, cabe destacar que as mudanças na política sul-americana, como a eleição de Mauricio Macri na Argentina e o impeachment de Dilma Rousseff, com a ascensão do vice-presidente, Michel Temer, ao poder, podem representar rupturas significativas com os projetos desenvolvidos na primeira década do século XXI. Embora sejam governos ainda em fase inicial, já vêm demonstrando que possuem uma inclinação à integração mais comercialista, focada nas vantagens comparativas. Assim, abandonam a perspectiva de fortalecimento de capacidades estruturantes e retomam os preceitos do alinhamento ao Consenso de Washington, que prevalecera nos anos 1990. Nesse sentido, o projeto do Gasoduto do Sul encontra um desafio vultoso para ser concretizado, em que pesem todos os benefícios que traria aos Estados da região.

\section{Referências Bibliográficas}

BOAS, Marina V. Integração Gasífera no Cone Sul: uma análise das motivações dos diferentes agentes envolvidos. Rio de Janeiro. Dissertação (Mestrado na área de Ciências em Planejamento Estratégico). Universidade Federal do Rio de Janeiro, 2004.

BRASIL. Estratégia Nacional de Defesa. Ministério da Defesa, Brasília, 2008.

British Petroleum [BP]. British Petroleum Statistical Review of World Energy June 2015. Londres, 2015. Disponível em: <https://www.bp.com/content/dam/bp/pdf/energy- 
economics/statistical-review-2015/bp-statistical-review-of-world-energy-2015-fullreport.pdf>. Acesso em: 04 jun 2016.

COSTA, Darc (org.). América do Sul: integração e infraestrutura. 1 ${ }^{a}$ Edição. Rio de Janeiro: Capax Dei, 2011.

COUTO, Leandro F. Desenvolvimento, Integração e Assimetrias: caminhos e descaminhos da aproximação regional na América do Sul. 1a Edição. Brasília: Fundação João Mangabeira, 2013.

FUCCILE, Alexandre. O Brasil e a América do Sul: (re)pensando a segurança e a defesa na região. Rev. Bra. Est. Def. ano 1, no 1, jul./dez., 2014. p. 112-146

FURTADO, Celso. A Pré-Revolução Brasileira. 1a Edição. Rio de Janeiro: Fundo de Cultura, 1962.

IIRSA [Iniciativa Para a Integração da Infraestrutura Regional Sul-Americana]. Carteira de projetos 2010: Planejamento Territorial Indicativo. 2010. Disponível em: <http://www.iirsa.org/BancoMedios/Documentos20PDF/lb10_carteira_de_projetos_iir sa_2010_p ortugues.pdf>. Acesso em: 25/02/2016.

IPEZONE [International Political Economy Zone]. On Chavez's Proposed Gas Cartel. 24/03/2007. Disponível em: <http://ipezone.blogspot.com.br/2007/03/on-chavezsproposed-gas-cartel.html>. Acesso em: 05 jun 2016.

LIMA, Maria R. S. de. O Lugar da América do Sul na Política Externa Brasileira. In: EXTERIORES, B. M. D. R. Obras de Integração Física na América do Sul. $1^{a}$ Edição. Brasília: MRE, 2007.

MAHAN, Alfred T. The Influence of Sea Power upon History: 1660-1783. Boston: Little Brown, 1894.

MARINGONI, Gilberto. A Revolução Venezuelana. 1a Edição. São Paulo: Editora Unesp, 2009.

MARTINS, José M. Q. Digitalização e Guerra Local como Fatores do Equilíbrio Internacional. Tese (Doutorado na área de Ciência Política). Universidade Federal do Rio Grande do Sul, 2008.

MARTINS, José M. Q. Relações Internacionais Contemporâneas 2012/2: estudos de caso em Política Externa e Segurança. 1aㅡ Edição. Porto Alegre: Ed. ISAPE, 2013.

OLIVEIRA, Lucas Kerr. Energia como Recurso de Poder na Política Internacional: geopolítica, estratégia e o papel do Centro de Decisão Energética. Tese (Doutorado na área de Ciência Política). Universidade Federal do Rio Grande do Sul, 2012.

PADULA, Raphael. As visões dominantes sobre a integração regional: o Regionalismo Aberto e a Iniciativa para a Integração de Infraestrutura Regional Sul-Americana (IIRSA). In: Darc Costa. (Org.). América do Sul: integração e infraestrutura. 1aㅡ Edição. Rio de Janeiro: Capax Dei, 2011, p. 143-208. 
PAZ, André da. Em Busca da Integração Interna: diagnóstico da matriz de transporte de integração sul-americana. In: COSTA, Darc (org.). América do Sul: Integração e Infraestrutura. 1a Edição. Rio de Janeiro: Capax Dei, 2011, p. 29-98.

PAZ, André da; NUNES, Rodrigo. Buscando as Complementaridades: diagnósticos das interconexões energéticas sul-americanas. In: COSTA, Darc (org.). América do Sul: integração e infraestrutura. 1ª Edição. Rio de Janeiro: Capax Dei, 2011, p. 99-142.

TILLY, Charles. Democracia. 1aㅡ Edição. Petrópolis: Editora Vozes, 2013.

VIZENTINI, Paulo F. América do Sul, Espaço Geopolítico Prioritário do Projeto Nacional Brasileiro. In: REBELO, Aldo; FERNANDES, Luiz; CARDIM, Henrique (orgs.). Política Externa do Brasil para o Século XXI. Câmara dos Deputados, 2003.

YERGIN, Daniel. A Busca: energia, segurança e reconstrução do mundo moderno. $1^{\text {a }}$ Edição. Rio de Janeiro: Intrínseca, 2014. 